\title{
Community Service Occupational Therapists: thriving or just surviving?
}

\author{
Kirsty van Stormbroek, BSc OT (UCT); MSc OT (UCT)** \\ Lecturer, Department of Occupational Therapy, School of Health Sciences, Faculty of Health Sciences, University of the \\ Witwatersrand
}

\section{Helen Buchanan, BSc OT; MSc OT; PhD OT}

Senior Lecturer, Division of Occupational Therapy, Department of Health and Rehabilitation Sciences, University of Cape Town

**The research described in this paper was conducted as a Master's Degree Student at the University of Cape Town

Introduction: Community Service was introduced to improve access to health care for all South Africans, yet little is known about the experiences of Community Service occupational therapists. This article describes the characteristics and general experiences of Community Service occupational therapists.

Methods: A national cross-sectional survey was undertaken. Data were collected with an online questionnaire to all occupational therapists completing Community Service in $2013(n=240)$. Data were analysed with IBM SPSS Statistics, version 21.0 , and responses to open ended questions were post-coded.

Results: A 44.3\% ( $n=104)$ response rate was achieved. Almost half the participants $(44.7 \%)$ were located rurally with 5 I.5\% working at primary level at least some of the time. Referrals were frequently received for wheelchair related services (6I.2\%), interventions related to child development $(49.5 \%)$, disability grant assessments $(36.9 \%)$ and treatment of adults with neurological conditions (39.8\%). While some therapists felt challenged (54.2\%) and frustrated (58.3\%), many $(75.0 \%)$ reported satisfaction from interacting with clients. Although the majority perceived the profession to be poorly recognised $(63.5 \%)$, most were proud to be occupational therapists (66.7\%).

Conclusion: Community Service occupational therapists are playing an important role in improving access to services but Community Service needs to be situated within a broader plan to extend and strengthen services in-line with government policy.

Keywords: Community service, occupational therapy, novice occupational therapist, professional identity

\section{INTRODUCTION}

Community Service (CS) has increased the number of rehabilitation professionals practicing within the public sector significantly'. State-employed occupational therapists and physiotherapists have reportedly increased by $33 \%$ and $40 \%$ respectively through the implementation of CS', a strategy introduced to address the challenges of a health system with a complex history.

The democratically elected government that assumed leadership of South Africa in 1994 inherited a health care system dominated by a curative, hospital-based approach and characterised by fragmentation $^{2}$, inequality, duplication and poor co-ordination of services ${ }^{3}$. The gross inequalities in resource allocation between public and private sectors and across provinces resulted in the majority of the population being under-served in terms of health care. Human resourcing of certain medical professionals (doctors, dentists and pharmacists) favoured the private sector and within the public sector, provinces with large urban hospitals attracted more staff ${ }^{2}$.

The National Health Plan for South Africa ${ }^{4}$ focusses on restructuring and transforming the health system based on a Primary Health Care (PHC) approach with priority attention on $\mathrm{PHC}$ facilities and personnel in rural and impoverished urban areas. Further plans to address the health care inequalities were described in the White Paper for the Transformation of Health Services ${ }^{5}$. Goals and objectives included unifying the fragmented health system, improving the availability and appropriateness of services and promoting equity, accessibility and utilisation of services. The equitable distribution of heath personnel throughout the country, and a focus on the rural, peri-urban and urban poor and aged, was described as one of the target areas for achieving this goal. Strategies employed to achieve this target included building and upgrading PHC facilities, introducing a rural allowance for health professionals and implementing a one year compulsory community service for graduating health professionals ${ }^{6}$.

Although challenges such as the quadruple burden of disease, insufficient control of epidemics, continued skewing of resource allocation towards the private sector, and flaws within the health system, have constrained progress towards achieving the goal of a unified health system for all, some important achievements have been realised at a policy and legislation level'. One of these policies, ratified by the Medical, Dental and Supplementary Health Service Professions Amendment Act of 1997, introduced compulsory CS for graduating health professionals ${ }^{7}$.

CS was implemented for doctors in 1998 and for other health professional groups, including occupational therapists (OT), in 2003. The system aimed to improve the provision of health care for all South Africans ${ }^{8}$, particularly in rural and previously under-served areas ${ }^{9}$. The effectiveness of CS is evidenced by the $20 \%$ increase in general medical practitioners in the public sector in 2006 and 2007. CS is considered to be one of the ten most effective health strategies implemented by the government since 1994'. This article reports part of the results of a larger study and aims to describe the demographic and practice characteristics of Community Service occupational therapists, and the general experiences of CS occupational therapists during their CS year in 2013.

\section{LITERATURE REVIEW}

A search of key databases was conducted (CINAHL, MEDLINE, Pubmed, Health Source: Nursing/Academic edition, Science Direct, Academic Search Premier and Africa-Wide Information) from January 2013 to November 2014 to identify research and grey 
Table I: Summary of published articles and grey literature related to community service for various health professional groups $(n=4 I)$

\begin{tabular}{|c|c|c|c|}
\hline $\begin{array}{l}\text { Professional } \\
\text { group }\end{array}$ & Author/s (Year) & Source & Research Aim \\
\hline \multirow{5}{*}{$\begin{array}{l}\text { Occupational } \\
\text { Therapists }\end{array}$} & Flieringa ${ }^{23}$ & $\begin{array}{l}\text { MSc (Occupational } \\
\text { Therapy) Minor Dissertation } \\
\text { (University of Cape Town) }\end{array}$ & $\begin{array}{l}\text { "To indiscriminately examine the impact of occupational } \\
\text { therapy student service learning experiences at role- } \\
\text { emerging, primary level health care sites on the adjustment } \\
\text { of graduates at similar sites during compulsory CS"23:37 }\end{array}$ \\
\hline & Holland, Middleton, \& Uys ${ }^{10}$ & $\begin{array}{l}\text { Occupational Therapy } \\
\text { International }\end{array}$ & $\begin{array}{l}\text { "To explore how novice occupational therapists } \\
\text { conceptualised professional confidence" } 10: 105\end{array}$ \\
\hline & Hess - April ${ }^{42}$ & $\begin{array}{l}\text { PhD Dissertation } \\
\text { (Occupational Therapy) } \\
\text { (University of the Western } \\
\text { Cape) }\end{array}$ & To explore CSOTs conceptualisation of occupational justice. \\
\hline & $\begin{array}{l}\text { CSOTs (Multiple authors, } \\
\mathrm{n}=23)^{26-40}\end{array}$ & $\begin{array}{l}\text { Focus (Official newsletter of } \\
\text { The Occupational Therapy } \\
\text { Association of South Africa) } \\
\text { Obtained via personal } \\
\text { communication }\end{array}$ & Not applicable: opinion piece. \\
\hline & $\begin{array}{l}\text { Maseko, Erasmus, Di Rago, } \\
\text { Hooper \& O’Reilly" }\end{array}$ & $\begin{array}{l}\text { South African Journal of } \\
\text { Occupational Therapy }\end{array}$ & $\begin{array}{l}\text { "To determine the factors that influence choice of } \\
\text { placement for community service amongst occupational } \\
\text { therapists in South Africa" } 1: 37\end{array}$ \\
\hline \multirow{4}{*}{ Doctors } & Reid $^{9}$ & South African Medical Journal & $\begin{array}{l}\text { "To evaluate the effects and impact of the first year of CS } \\
\text { intervention against [DOH objectives]":329 }\end{array}$ \\
\hline & Kolosa $^{12}$ & South African Medical Journal & Not applicable: opinion piece. \\
\hline & $\begin{array}{l}\text { Nemutandani, Maluleke, \& } \\
\text { Rudolph }^{13}\end{array}$ & South African Medical Journal & $\begin{array}{l}\text { "To assess the work experiences of [CS doctors] in the } \\
\text { public hospitals of Limpopo Province during 2003" } 13: 180\end{array}$ \\
\hline & Ross \& Reid ${ }^{14}$ & South African Family Practice & $\begin{array}{l}\text { "To gain understanding of the motivations of CS officers to } \\
\text { continue working in the same DH for a subsequent year } \\
\text { after their obligatory year is over" } 14: 249\end{array}$ \\
\hline PTs\# & Ramklass $^{15}$ & $\begin{array}{l}\text { Health and Social Care in the } \\
\text { Community }\end{array}$ & $\begin{array}{l}\text { "(To explore) how the first cohort of physiotherapists } \\
\text { experiences their year-long CS and how they felt their } \\
\text { undergraduate training prepared them for practice"|5:522 }\end{array}$ \\
\hline \multirow[t]{2}{*}{ Nurses } & Thopola, Kgole, \& Mamogobo ${ }^{16}$ & $\begin{array}{l}\text { African Journal for Physical } \\
\text { Health Education, Recreation } \\
\text { \& Dance }\end{array}$ & $\begin{array}{l}\text { "To explore and describe the experiences of newly qualified } \\
\text { nurses who were trained in the University of Limpopo... } \\
\text { CSs within public health establishments of Limpopo } \\
\text { Province..." } 16: 169\end{array}$ \\
\hline & Beyers $^{24}$ & $\begin{array}{l}\text { Magister Curationis Minor } \\
\text { Dissertation } \\
\text { (University of the Western } \\
\text { Cape) }\end{array}$ & $\begin{array}{l}\text { "To describe the experiences of CS practitioners during } \\
\text { their CS at a rural health facility" } 24: 9\end{array}$ \\
\hline SLTs \& As* & Wranz $\underline{25}$ & $\begin{array}{l}\text { MPhil (Health Science } \\
\text { Education) Dissertation } \\
\text { (Stellenbosch University) }\end{array}$ & $\begin{array}{l}\text { "To identify the potential gaps that exist between }(\mathrm{CS}) \\
\text { professionals' perceived readiness and the demands of the } \\
\text { reality (context) in which they have to function"25:12 }\end{array}$ \\
\hline \multirow{3}{*}{ Dieticians } & $\begin{array}{l}\text { Visser, Marais, Du PLessis, } \\
\text { Steenkamp, \& } \text { Troskie }^{17}\end{array}$ & $\begin{array}{l}\text { South African Journal of } \\
\text { Clinical Nutrition }\end{array}$ & $\begin{array}{l}\text { "To investigate the experiences and attitudes of CS } \\
\text { dieticians... to determine their perception of the success of } \\
\text { the year as a whole and to assess whether the knowledge } \\
\text { and skills of graduates improved" 17:10 }\end{array}$ \\
\hline & Paterson, Green, \& Maunder ${ }^{15}$ & Health Policy & $\begin{array}{l}\text { "To examine and explore the factors affecting the } \\
\text { professional development of dieticians during CS"18:288 }\end{array}$ \\
\hline & Parker et al ${ }^{19}$ & Public Health Nutrition & $\begin{array}{l}\text { "To evaluate the successes and shortcomings of the CS } \\
\text { programme implemented by the DOH in South Africa by } \\
\text { evaluating CS dieticians experiences and challenges during } \\
\text { the } 2009 \text { CS year" } 19: 1411\end{array}$ \\
\hline \multirow{3}{*}{$\begin{array}{l}\text { Clinical } \\
\text { psycho- } \\
\text { logists }\end{array}$} & Rohleder, Miller, \& Smith ${ }^{20}$ & $\begin{array}{l}\text { South African Journal of } \\
\text { Psychology }\end{array}$ & Not applicable: opinion piece. \\
\hline & Pillay \& Harvey ${ }^{21}$ & $\begin{array}{l}\text { South African Journal of } \\
\text { Psychology }\end{array}$ & $\begin{array}{l}\text { "To survey the experiences of the country's entire first } \\
\text { group of CS clinical psychologists" } 25: 259\end{array}$ \\
\hline & Swarts 22 & $\begin{array}{l}\text { South African Journal of } \\
\text { Psychology }\end{array}$ & Not applicable: opinion piece. \\
\hline \multicolumn{4}{|c|}{ \# PTs: Physiotherapists } \\
\hline
\end{tabular}


literature (dissertations and theses) related to CS in the different health professional groups. As information about CS occupational therapists' experiences was specifically needed, hand searches were undertaken of the Focus (official newsletter of the Occupational Therapy Association of South Africa (OTASA)) from 2004 to 2014 to locate articles written by CS occupational therapists on their experiences. The heads of all occupational therapy education programmes in South Africa $(n=8)$ in 2013 were also contacted to identify studies that were either unpublished or still in progress.

Fourteen journal articles ${ }^{9-22}$ and three Masters dissertations ${ }^{23-25}$ were identified from the search (see Table I on page 64 for a summary of the articles that were retrieved). Hand searches located 19 opinion pieces involving 23 authors ${ }^{26-41}$. E-mail correspondence with the heads of occupational therapy education programmes at the time confirmed that no studies on CS occupational therapists' experiences had been conducted, but one related $\mathrm{PhD}$ study ${ }^{42}$ was in progress.

At the time of the study, no research exploring the experiences of CS occupational therapists was located. One article on the conceptions of the professional confidence of eight CS occupational therapists in KwaZulu Natal ${ }^{43}$, although not directly relevant to this study, provided helpful background information. The article reported that CS occupational therapists in KwaZulu Natal were either sole-practitioners or worked in a small team of occupational therapists and sometimes alongside other CS rehabilitation staff. Some worked within well-established departments, while others were required to re-establish departments or start new services. Although informal support structures have been developed for CS occupational therapists in KwaZulu Natal, the National Department of Health (DOH) considers practitioners to be qualified and thus fit-for-practice, and do not provide any formal mentorship ${ }^{43}$.

A doctoral thesis exploring CS occupational therapists' conceptualisation of occupational injustice was in process ( $\mathrm{L}$. Wegner, email communication, March 25, 2013), with preliminary findings highlighting the severe constraints participants experienced in applying the concept of occupational justice due to the medical model dominated health system (L. Hess-April, email communication, January I4, 2014). A masters study found that final year occupational therapy students perceived role-emerging placements during their undergraduate education as equipping them better for the challenges of $\mathrm{CS}^{23}$. An undergraduate project described the factors influencing the choice of CS placement for a group of 2012 CS occupational therapists ". Access to personal development opportunities was considered important by $75 \%$ of the participants and $66 \%$ indicated a preference for urban rather than rural posts. However, the experience of therapists within these posts was not explored".

Opinion pieces $(n=19)$ accessed during this period provided valuable insights on the experiences of CS occupational therapists. Challenges included working with limited resources ${ }^{26-32}$, language barriers ${ }^{26,29-31,41}$ and a patient population faced with costly travel to health care facilities $26,28,33$. Facing the needs of communities was reportedly difficult and even overwhelming at times $32,35,41,44,45$, but provided opportunities to make a difference ${ }^{27,37}$. Challenges encouraged resourcefulness and an ability to adapt $\mathrm{t}^{26,28,36,40}$. The CS year facilitated the development of experience, knowledge and confidence which was enriched through exposure to colleagues from other universities ${ }^{30,32,34-48}$. The gratitude of patients, their families and communities, was identified repeatedly as a highlight of the CS experience $27,28,30,32,33,37,44$. Two therapists accentuated the crucial role that occupational therapy assistants played in their practice ${ }^{37,44}$. A number of CS occupational therapists emphasised the importance of appreciating that the approach taken to CS is a choice and that therapists need to take responsibility for their learning and contribute to the communities in which they work ${ }^{26,36,41,45}$. While these experiences communicate important views, they cannot be generalised to the CS occupational therapist population in any given year. It is important to note that these contributions spanned 10 years and were written by CS occupational therapists who were either approached to share their experience, or who had submitted an article of their own volition, therefore, their experiences may differ from other therapists.

While this literature review identified studies about the experiences of several health professional groups, it revealed a paucity of research on the experiences of CS occupational therapists and the services they provide, thus supporting the need for this study. Understanding the experiences of CS occupational therapists will assist in the appropriate preparation of these novice occupational therapists and will inform the support that is required for the development of CSOTs and their services. Furthermore, CS occupational therapists' experiences provide insight into the underserved therapy contexts into which occupational therapy services are being extended.

\section{METHOD}

\section{Study design}

A descriptive cross-sectional research design was used.

\section{Population and sampling}

The population consisted of all occupational therapists who were allocated CS placements for 2013 by the National Department of Health $(n=24 I)$. Therapists who were allocated placements but did not take them up were excluded $(n=I)$. The population was thus 240. To capture as broad a spectrum of experience as possible ${ }^{19}$ total population sampling was employed.

\section{Instrumentation}

As compulsory CS is unique to South Africa and a suitable instrument was not found, a survey was designed for the study. The development and content of the survey was guided by a review of the literature. The survey for the full study consisted of two sections: Section A contained demographic and practice information (1 9 items), and general CS experience (48 descriptors), while Section $B$ focused on upper limb rehabilitation. This article reports only the results for Section A. Question types included numerical items, dichotomous and multiple response items, linear numeric scales, and open-ended questions. To allow participants to qualify their answers to closed-ended questions, space was made for additional comments. Descriptors for the section on general CS experience were extracted from published articles on novice practitioners' experiences of practice ${ }^{46-54}$. Descriptors were grouped into four areas of professional practice: knowledge and skill in practice ( 13 items), professional identity and recognition ( 8 items), supervision and support ( 7 items), and positive and negative personal descriptors (20 items). Participants could select more than one descriptor and were given the opportunity to explain their choice. A copy of the questionnaire is available on request from the first author. The survey was self-administered and created with Fluidsurvey software ${ }^{55}$, and was available in both English and Afrikaans (the languages of instruction within the eight occupational therapy programmes).

\section{Pilot testing}

The draft questionnaire was pilot tested in September and October 2013 with three groups of occupational therapists: upper limb rehabilitation experts $(n=6)$, fourth year students $(n=5)$ and therapists who had previously completed their CS $(n=7)$. The aim of the pilot studies was to strengthen content validity, face validity and utility of the instrument. Electronic and hard copy questionnaires were used in this process. Feedback from participants highlighted the need for more adequate definitions of various terms. For example, the definition for "cultural competence" within the questionnaire raised multiple queries and was thus changed to a more comprehensive definition. Participants identified various formatting errors including where insufficient space had been left to add comments. Participants also provided feedback on the time taken to complete the questionnaire so that this could be amended in the participant information sheet. 


\section{Procedure}

Participants were recruited in several ways (telephonically, through text messages, post, email or Facebook) to maximise the response rate. Data were collected between November 2013 and January 2014 so that responses could be based on at least 10 of the 12 month contract. Questionnaires were completed electronically where possible. Hard copy questionnaires with pre-paid envelopes were posted to participants who did not have access to telephones or e-mail. An e-mail reminder was sent to increase the response rate. The information sheet included an explanation that incentives would be offered to those who completed the questionnaire. All participants submitting a completed questionnaire received a discount voucher for splinting material, and were entered into a lucky draw for an occupational therapy textbook sponsored by a book company. The incentives were minor and thus did not lead to undue inducement.

\section{Data management and analysis}

Data were stored using Fluidsurvey software ${ }^{55}$ with its guaranteed security settings to ensure confidentiality. Data for manually completed and e-mailed questionnaires were entered into Fluidsurvey ${ }^{55}$ the first author, and checked for accuracy by a research assistant who compared entries against the hard copy questionnaires. Data were analysed with IBM SPSS Statistics $21.0^{56}$. Numerical data were checked for normality and the appropriate measures of central tendency and dispersion were calculated. Frequencies and proportions were determined for categorical data. Where necessary, categories were collapsed before analysis. Pearson's Chi-square test of association was used to determine whether there were significant relationships between variables. Odds ratios (OR), which measure the association between exposure and a specific outcome, were calculated to further explore associations. The OR denotes the odds of an outcome occurring given exposure to a specific condition or factor, when compared to the odds of the outcome occurring in the absence of this condition/ factor $^{57}$. Responses to open-ended questions were post-coded and grouped into categories by the first author, and checked for clarity and coherence by the second author. Any disputes were discussed by the authors until consensus was reached.

\section{Ethics}

Ethics approval was obtained from the University of Cape Town Human Research Ethics Committee (HREC approval number: $55 \mathrm{I} / 20 \mathrm{I}$ ). Participants provided informed consent. Participants were asked to provide their names to ensure that multiple responses from the same participants were not included in the analysis. To protect confidentiality, questionnaires were allocated a number according to the list of registered CS occupational therapists. Once checks had been done to ensure only one questionnaire had been submitted per participant, names were removed from participant responses by the first author.

\section{RESULTS}

The response rate was $43.3 \%(n=104)$. The sample represented $21.4 \%$ males and $44.2 \%$ females in the population. One response was excluded as no questions beyond the consent section had been answered. The analysis thus included 103 responses, representing $42.9 \%$ of the population of CS occupational therapists in 2013 . Where $\mathrm{n}<103$ for items, missing responses for that item are indicated.

\section{Demographic and practice profile of participants}

The median age was 23.0 (Range: 21.0 - 30.0) years, and most participants had qualified in 2012 (Range: 2008 - 20I3). The participants' demographic and practice profiles are shown in Table II.

Just over half $(55.3 \%)$ of the participants were placed in urban settings and worked within facility and community-based services $(54.5 \%)$, with at least some time spent within primary levels of care (51.5\%). Referrals were commonly received for specific services or change modalities (for example, wheelchair services and splinting)
Table II: Demographic \& practice profile $(n=103)$

\begin{tabular}{|c|c|}
\hline Variable & No. (\%) \\
\hline \multicolumn{2}{|l|}{ Gender } \\
\hline Male & $3(2.9)$ \\
\hline Female & $100(97.1)$ \\
\hline Total & $103(100)$ \\
\hline \multicolumn{2}{|l|}{ University } \\
\hline University I & II (10.7) \\
\hline University 2 & $\mathrm{II}(10.7)$ \\
\hline University 3 & $9(8.7)$ \\
\hline University 4 & $9(8.7)$ \\
\hline University 5 & $20(19.4)$ \\
\hline University 6 & II (I0.7) \\
\hline University 7 & $21(20.4)$ \\
\hline University 8 & $11(10.7)$ \\
\hline Total & $103(100.0)$ \\
\hline \multicolumn{2}{|l|}{ Province } \\
\hline Eastern Cape & $17(16.5)$ \\
\hline Gauteng & $27(26.2)$ \\
\hline Free State & $4(3.9)$ \\
\hline KwaZulu Natal & $20(19.4)$ \\
\hline Limpopo & $8(7.8)$ \\
\hline Mpumalanga & $14(13.6)$ \\
\hline North West & $\mathrm{I}(\mathrm{I})$ \\
\hline Northern Cape & $5(4.9)$ \\
\hline Western Cape & $7(6.8)$ \\
\hline Total & $103(100.0)$ \\
\hline Service Level & No. (\%) \\
\hline Primary & $33(32.0)$ \\
\hline Secondary & $32(31.1)$ \\
\hline Tertiary & $13(12.6)$ \\
\hline Primary \& Secondary & $18(17.5)$ \\
\hline Secondary \& Tertiary & $2(1.9)$ \\
\hline Primary \& Tertiary & $\mathrm{I}(\mathrm{I})$ \\
\hline Primary, Secondary \& Tertiary & $\mathrm{I}(\mathrm{I})$ \\
\hline $\begin{array}{l}\text { Other (psychiatric facility, provincial hospital or } \\
\text { military services) }\end{array}$ & $3(2.9)$ \\
\hline Total & $103(100.0)$ \\
\hline Location & No (\%) \\
\hline Rural & $46(44.7)$ \\
\hline Urban & $57(55.3)$ \\
\hline Total & $103(100.0)$ \\
\hline Setting & No (\%) \\
\hline Facility (services delivered at DOH facility) & $36(35.0)$ \\
\hline $\begin{array}{l}\text { Community (services delivered in the } \\
\text { community) }\end{array}$ & II (I0.7) \\
\hline Both & $56(54.4)$ \\
\hline Total & $103(100.0)$ \\
\hline
\end{tabular}

and medical diagnoses (for example, developmental delay and adult neurology) (see Figure I on page 67 for details). 


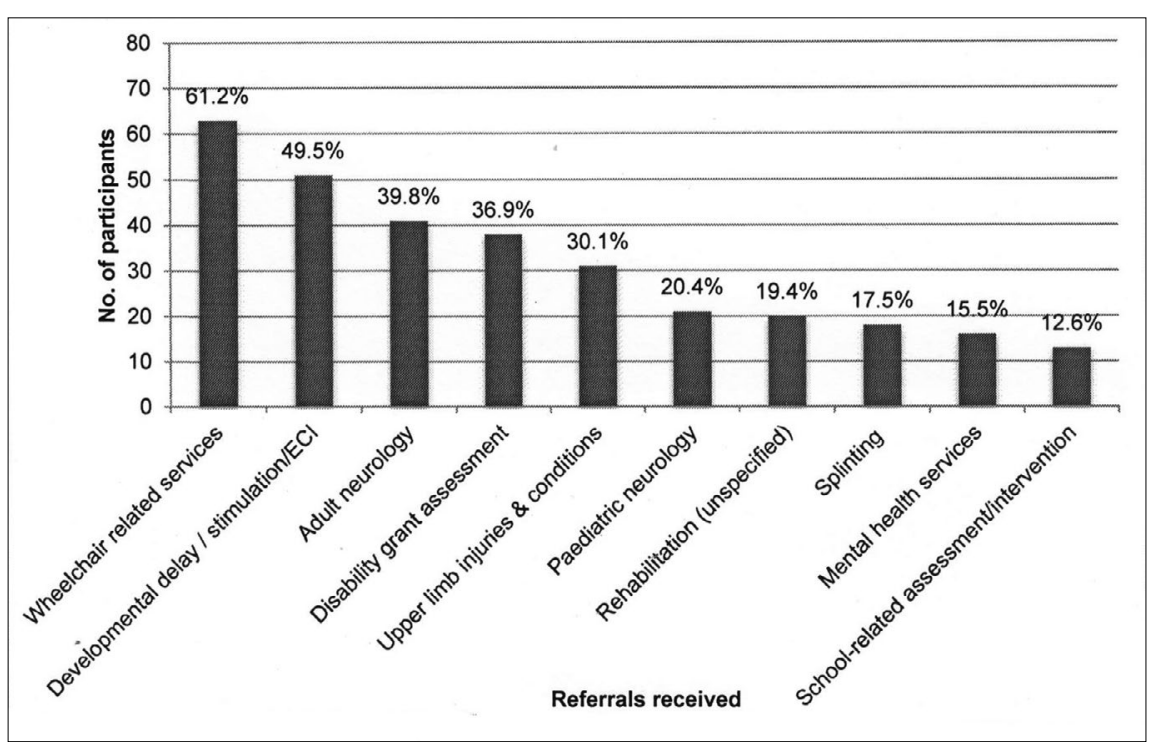

Figure I: Common reasons for referral $(n=103)$

Table III: Opportunities to observe other occupational therapists treating patients $(n=65)$ *

\begin{tabular}{|c|c|c|c|}
\hline $\begin{array}{l}\text { Opportunities } \\
\text { available }\end{array}$ & Theme & Category & $\begin{array}{l}\text { No. } \\
\text { (\%) }\end{array}$ \\
\hline \multirow[b]{2}{*}{ Yes $(n=44)$} & $\begin{array}{l}\text { Enabling \& } \\
\text { enriching } \\
\text { factors }\end{array}$ & $\begin{array}{l}\text { - Observation } \\
\text { encouraged, enabled } \\
\text { or allowed by setting } \\
\text { - Able to seek } \\
\text { opportunities for } \\
\text { observation beyond } \\
\text { setting/facility } \\
\text { - Observing OTs with } \\
\text { experience/expertise }\end{array}$ & $\begin{array}{c}19 \\
(29.2) \\
3(4.6)\end{array}$ \\
\hline & $\begin{array}{l}\text { Limiting } \\
\text { factors }\end{array}$ & $\begin{array}{l}\text { - Time, workload } \\
\text { and distance minimise } \\
\text { frequency } \\
\text { - Observing OTs with } \\
\text { minimal experience / } \\
\text { expertise } \\
\text { - Participants requested } \\
\text { to assist colleague } \\
\text { during treatment } \\
\text { and felt that this } \\
\text { limited learning } \\
\text { potential }\end{array}$ & $\begin{array}{c}17 \\
(26.2) \\
8(12.3) \\
3(4.6)\end{array}$ \\
\hline \multirow[b]{2}{*}{ No $(n=2 I)$} & $\begin{array}{l}\text { Practical } \\
\text { limitations }\end{array}$ & $\begin{array}{l}\text { - Only OT in treatment } \\
\text { area/site } \\
\text { - Excessive workload }\end{array}$ & $\begin{array}{l}10 \\
(15.4) \\
6(9.2)\end{array}$ \\
\hline & $\begin{array}{l}\text { Attitude } \\
\text { and } \\
\text { opportunity }\end{array}$ & $\begin{array}{l}\text { - Limited or no } \\
\text { opportunity available } \\
\text { - Observation not } \\
\text { allowed or discouraged }\end{array}$ & $\begin{array}{l}2(3.1) \\
2(3.1)\end{array}$ \\
\hline
\end{tabular}

Sixty-five participants responded to the item about opportunities to observe other occupational therapists treat patients. This included colleagues who may, or may not have had more experience. The majority $(67.7 \%)$ reported having opportunities to observe other occupational therapists treat patients while $32.3 \%$ did not have such opportunities. Factors influencing whether or not they were able to observe colleagues treat patients are shown in Table III.

\section{Descriptors of general CS experience}

Descriptors (extracted from literature on novice clinicians' experiences) capturing participants' feelings associated with their CS experience are reported in the sub-sections representing different areas of professional practice, namely: knowledge and skill in practice, professional identity and recognition, support and supervision, and personal descriptors (positive and negative descriptors participants used to describe their CS experience). Descriptors are indicated in italics in the text - only those with high frequencies or those that were strongly emphasised are reported. As stated earlier, comments that explained participants' reasons for selecting a particular descriptor were organised into categories. These are reported in the text with the number of participants whose comments were captured for each category (indicated by an n-value).

\section{Knowledge and skill in practice}

Frequencies for descriptors relating to the use of knowledge and skill in practice are illustrated in Figure II on page 68.

Most of the participants felt challenged $(54.2 \%)$ due to a lack of physical or human resources $(n=13)$, clinical challenges $(n=8)$ or dealing with differences in culture and language $(n=5)$. Therapists who felt challenged were more than three times more likely to also experience communication difficulties (OR 3.44). This result was significant $(95 \% \mathrm{Cl}$ : I. $29-9.18 ; \mathrm{p}=0.014)$.

A relatively high percentage of participants perceived a need for specific knowledge in assessment and treatment (43.8\%), which was largely linked to conditions for which they commonly received referrals $(n=18)$. This need for specific knowledge was influenced by contextual factors such as late presentation of injuries when surgery is no longer an option $(n=1)$, limited resources $(n=3)$, restricted access to information or professional development $(n=2)$, and lack of guidance from senior therapists $(n=l)$. Participants felt that the breadth of knowledge required could not always be met by knowledge gained at university, which was perceived as lacking in detail or depth $(n=6)$. Despite this, many participants felt okay with not knowing everything (42.7\%). They attributed this to an appreciation for life-long learning $(n=\mathrm{I})$ as reflected in the following comment from a participant.

I have learnt to stop comparing my beginning to someone else's middle. I am only just starting out in the OT profession, with time I will grow in knowledge. (Participant 8I)

Others felt that not knowing everything was to be expected given the broad scope of occupational therapy $(n=3)$, linked it to knowing what you don't know $(n=4)$, or felt it was a useful point of departure for broadening their knowledge $(n=2)$. Participants who felt encouraged to reflect critically on practice felt that this was motivated by the need to ensure quality service delivery $(n=7)$, or necessitated by an absence of feedback and direction from supervisors $(n=6)$. Conversely, others felt the opportunity to reflect with colleagues and supported critical reflection $(n=7)$. Participants who were dissatisfied with supervision were three times more likely not to report being encouraged to reflect critically on their practice (OR 3. I7; 95\% Cl: I.29- 7.79; $p=0.012$ ).

\section{Professional identity and recognition}

Frequencies for descriptors related to professional identity and recognition are shown in Figure III on page 68.

Two-thirds of the participants were proud to be an occupational therapist which some participants linked with bringing meaning to, meeting needs of and making a difference in patients' lives $(n=8)$, developing pride, passion and confidence in the profession $(n=5)$, or to their growing appreciation of the unique contribution of the profession $(n=4)$. Participants who reported a sense of pride were four times more likely to have a strong identity as an occupational therapist (OR 4.9I; 95\% Cl: I.78 - 13.54; p=0.002). Some par- 
ticipants found their identity challenged by a limited understanding of the role of the occupational therapist in practice settings $(n=4)$. Participants who did not report having a strong identity as an occupational therapist were three times more likely to be dissatisfied with supervision (OR 3.41 ; $95 \% \mathrm{Cl}$ I.38 - 8.44; $\mathrm{p}=0.008$ ). Almost

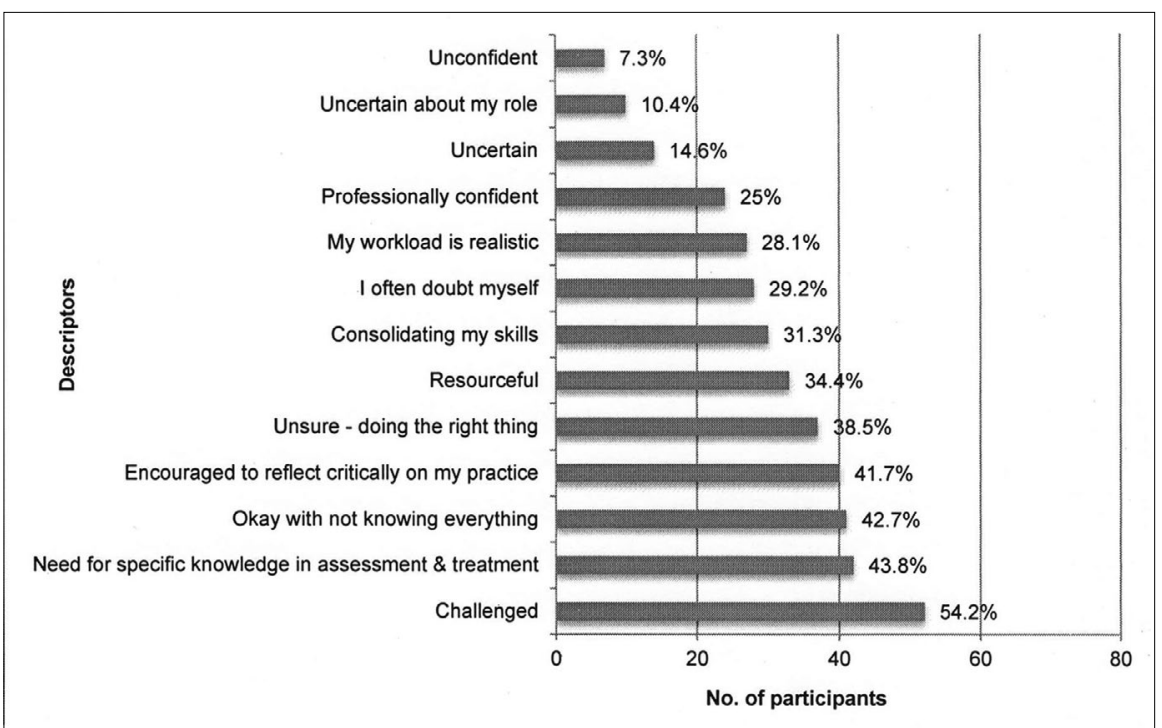

Figure II: Descriptors for Knowledge and skill in practice $(n=96)$

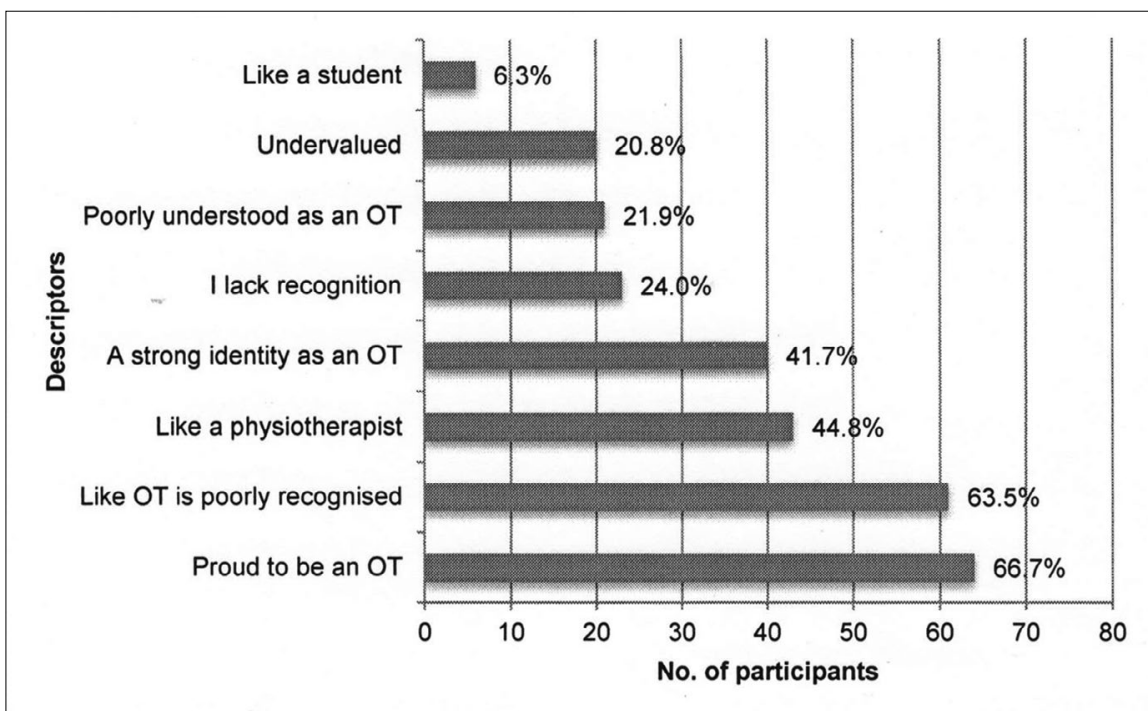

Figure III: Descriptors for Professional identity and recognition $(\mathrm{n}=96)$

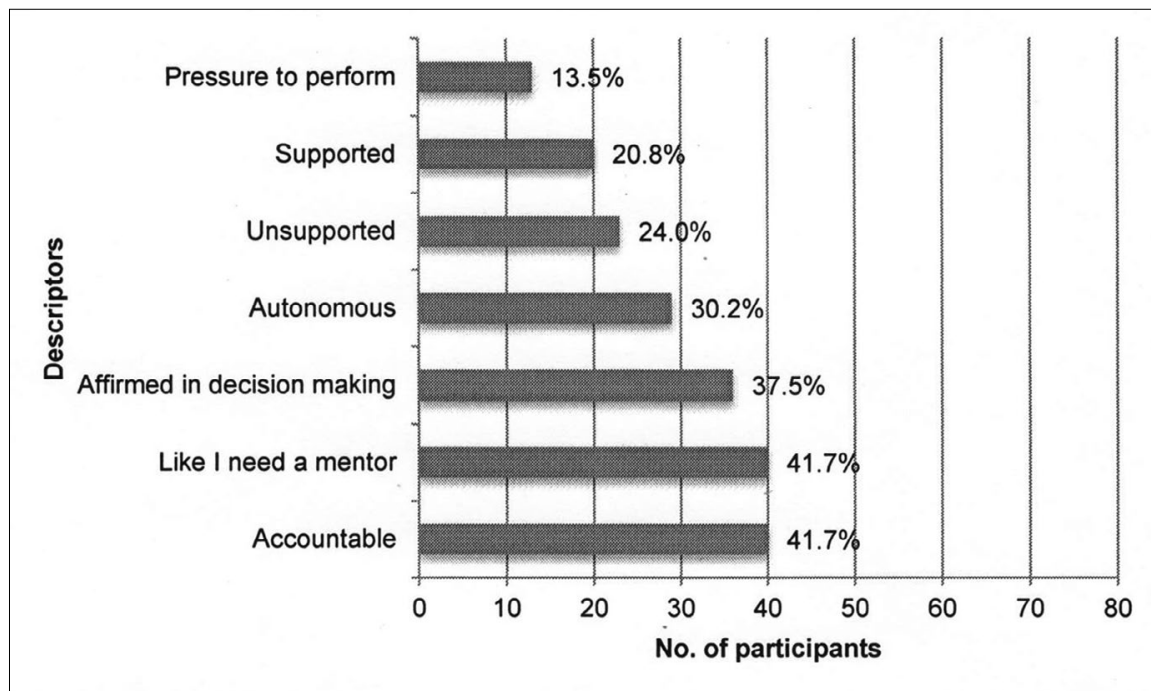

Figure IV: Descriptors for Supervision and support $(n=96)$ half the participants reported feeling like a physiotherapist (44.8\%) and provided a variety of reasons for this. One therapist explained:

When communication is difficult I turn to exercises which I can easily show patients. This often makes me feel like a physiotherapist.

\section{(Participant 60)}

Some $(n=7)$ linked their sense of feeling like a physiotherapist to not having activities, equipment or time to enable activity-based treatment, while others $(n=6)$ felt that patients with some conditions (e.g. cerebral palsy and stroke) in the very acute stages of recovery often required a similar approach to that of the physiotherapist. Participants reported feeling like a physiotherapist $(n=5)$ where physiotherapy services were absent or limited, or when they worked closely with physiotherapists. Three participants linked this to lacking appropriate occupational therapy support or role model. Two participants reported that this feeling faded as they consolidated their identity as an occupational therapist and their occupation-centred practice grew.

Feeling poorly understood as an OT was significantly associated with feeling that $O T$ is poorly recognised (OR 4.47; 95\% Cl: I.0I - I.89; $\mathrm{p}=0.025$ ). The descriptor OT is poorly recognised was reported by $63.5 \%$ of participants. This was linked to being mistaken as a physiotherapist by the health team and the public $(n=9)$, and a limited understanding of the role and value of occupational therapy by the team and the community $(n=14)$. The following comments suggest that some of the meaning of occupational therapy may get lost in translation:

There is no Zulu name for OT which makes it challenging to explain what we do or our role in the hospital. We often have to refer to ourselves as 'dokatela wamatambo' (doctor of the bones i.e. physio) or 'dokatela wesingane' (doctor of the children). (Participant 82)

In the rural areas people only recognise dieticians, speech therapists and physiotherapists as members of the rehab (rehabilitation) team because they use association to identify professions, e.g. physio (bones) dieticians (food) speech and audiology (ears)... so as OTs, we lack that one specialty that singles us out. (Participant 5)

\section{Support and Supervision}

Figure IV demonstrates frequencies for descriptors related to supervision and support.

Many participants (4I.7\%) felt like I need a mentor and their comments revealed that they coveted the guidance, advice, feedback and role-modelling that a mentor could offer in order to meet the demands of their work environments $(n=16)$. Four participants reported seeking mentorship with varying levels of success. Satisfaction with supervision was protective against needing a mentor (OR $0.1 \mathrm{I} ; 95 \% \mathrm{Cl}$ : $0.03-0.34 ; p<0.00 I$ ), and participants who had an occupational therapist as a supervisor were less likely to report needing a mentor (OR I.39; 95\% Cl: I.0I - I.89; $\mathrm{p}=0.040$ ).

Twenty-four percent felt unsupported due to a lack of supervision $(n=3)$ and support from 


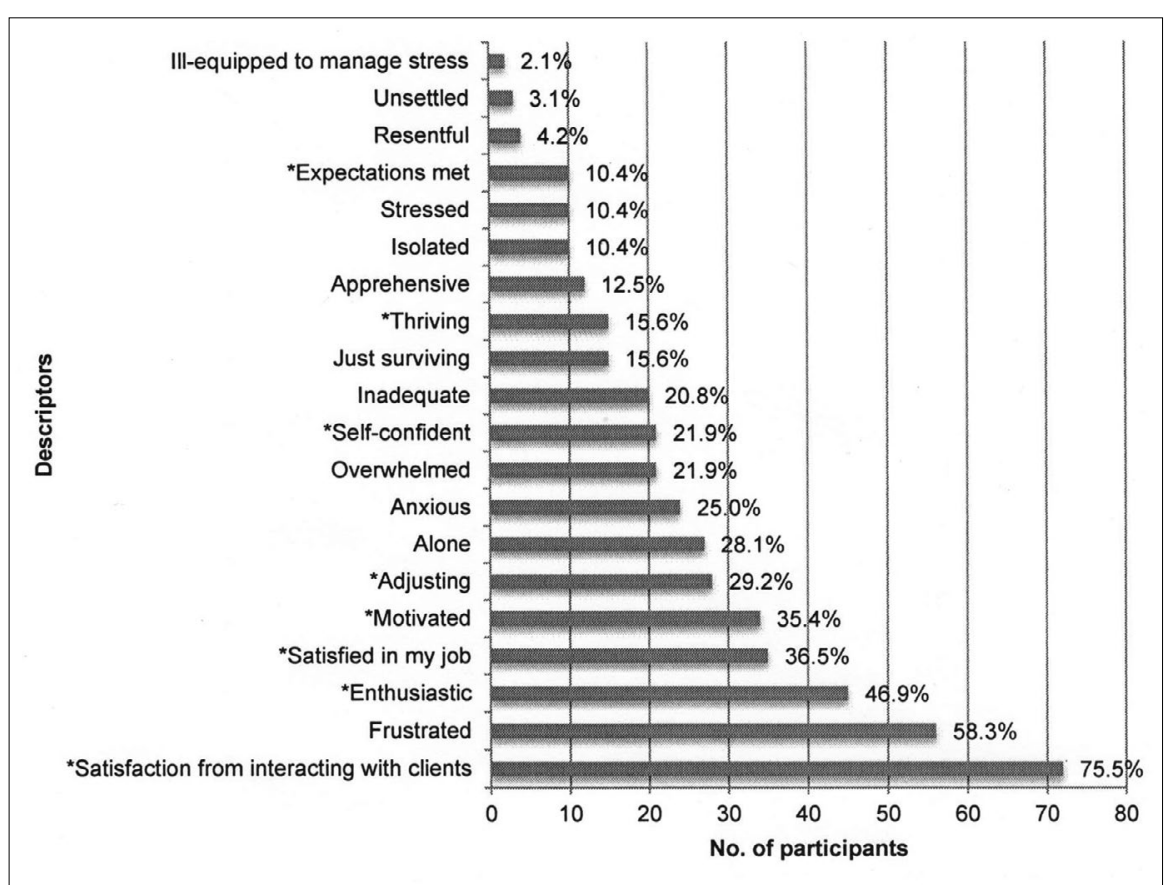

Figure V: Positive* and negative personal descriptors

the health team $(n=4)$. Support from the team $(n=4)$ and supervision $(n=3)$ contributed to a similar percentage $(20.8 \%)$ feeling supported. Many participants considered themselves accountable $(41.7 \%)$ with some linking this to working alone and thus needing to be (solely) accountable for what is done $(n=2)$, while others linked it to their direct responsibility to patients $(n=3)$, feeling they were in some way accountable to others $(n=4)$ or felt a sense of personal responsibility $(n=3)$.

\section{Personal descriptors}

Responses to personal descriptors are illustrated in Figure $V$.

The most selected descriptor was deriving a sense of satisfaction from interacting with clients $(75.0 \%)$. Comments suggested that this was linked with opportunities to witness improvement in patients' functioning $(n=5)$, receiving patient gratitude $(n=5)$, making meaningful contributions to patients' lives $(n=6)$, positive feedback from others $(n=I)$, and experiencing good therapeutic relationships $(n=4)$. Participants felt this occurred despite the language barrier $(n=6)$ and some linked it to being able to appreciate new cultures $(n=2)$.

Adjusting was characteristic for some $(n=28)$ with comments suggesting that this occurred as the year progressed $(n=2)$, was related at times to adjusting to rural living, culture and language differences $(n=3)$ or to working within or around contextual limitations $(n=6)$ as noted in this quote:

I did feel like this entire year was about adjusting. Adjusting to: working on my own (without supervision); working without equipment; working in a [multi-disciplinary team]; working with limited/no resources; and working with poor management and support from the clinic. And I feel that all of those were valuable learning experiences. (Participant 7I)

Despite the change and challenges experienced, CS was perceived as valuable. A positive approach was echoed by those that reported feeling enthusiastic (46.9\%). Some participants $(n=6)$ felt enthusiastic at first, or only at times depending on contextual factors and patients' attitude towards treatment, while others focused on the great need for services and the potential to make a significant contribution in the community $(n=6)$. A smaller group described themselves as thriving (I5.6\%) as they were able to meet the challenges presented by their particular context $(n=5)$.

Frustration was common (58.3\%) and was linked to resource limitations $(n=17)$ including equipment, materials, absent or limited budgets, long delays in the delivery of equipment, assistive devices or wheelchairs, limited transport and limited working space. As one participant described:

Equipment needed is refused and instead we are provided with unnecessary equipment. The BASICS are not provided and it is extremely frustrating, also those who are ill/disabled are constantly disadvantaged by certain members who are of higher power. (Participant 104)

This suggests unprofessional and unethical practice as another source of frustration. The attitudes and behaviour of clinical, administrative and managerial staff were perceived to not support quality service delivery and teamwork. Two participants highlighted the negative impact they felt this had on patient rights and services. Communication difficulty across language barriers was a further source of frustration $(n=3)$ as were poorly operating administrative and managerial systems $(n=I I)$. Further sources of frustration included limited learning opportunities $(n=2)$, lack of supervision and support $(n=2)$ and the impact of poor motivation on their CS experience. Frustration also arose from clinical challenges $(n=4)$, including the unavailability of specialist services (e.g. orthopaedic surgery) that resulted in patients' loss of function. Communication difficulties (OR 3.48; $95 \% \mathrm{Cl}$ I $.32-9.20 ; p=0.0 \mathrm{I} 2$ ), insufficient equipment to treat patients with upper limb injuries (OR $0.33 ; 95 \% \mathrm{Cl} 0.14-0.8 \mathrm{I} ; \mathrm{p}=0.0 \mathrm{I} 6)$ and dissatisfaction with supervision (OR $0.33 ; 95 \% \mathrm{Cl} 0.14-0.82 ; p=0.017$ were significantly associated with frustration.

Other negative personal descriptors were selected less frequently. Some participants felt alone (28.1\%). One participant stated, VERY! Cannot stress this enough! while another commented: At the beginning of the year I was incredibly alone, at work and after hours. An absence of colleagues, minimal guidance and difficult interpersonal or management systems contributed to feeling alone at work $(n=12)$. Twenty-five percent felt anxious which was at times related to applying knowledge and skill $(n=6)$ or being solely responsible for services $(n=2)$ as illustrated by this quote:

My first day at work went like this: the head physio greeted me, gave me a key and said, 'Here are the keys for your department'. No other help or guidance was given and when I asked or phoned the district, I was just referred on to another person. (Participant 2I)

Other reasons for anxiety included high workloads $(n=3)$, communication difficulties $(n=1)$ or future work after CS $(n=3)$. Similar reasons were linked to feeling that "I am just surviving" (I5.6\%). One participant stated that this was related to severe staff shortages while another attributed it to the amount of "admin" that was required. Similarly, feeling overwhelmed was not uncommon (21.9\%) with two participants feeling that this characterised their experience in the beginning of the year, and others $(n=10)$ linking it to the need or workload they were faced with. Two participants felt that a lack of knowledge and experience contributed to this feeling and another linked it to all the change associated with the CS year.

The study findings indicate that rural practice is beneficial for CS occupational therapists and should receive priority attention during undergraduate preparation as noted in the following comment:

Working in a rural setting is a valuable experience that all OTs should have to do. Those that work in tertiary hospitals are unaware of the challenges these individuals face being so rural. More should be done at varsity to equip therapists with actual community work and more focus placed on empowering individuals in the community with regards to skills training, job placements, and just community life in general - how to have a sustainable life (education on agriculture, proper pre-natal education and training etc.). (Participant 104) 


\section{Discussion and implications}

Improving rural and underserved communities' access to health care is central to the purpose of CS $^{9}$. It is therefore disappointing that at the time of the study, I I years after the implementation of CS for occupational therapists, less than half the participants in this study $(44.7 \%)$ were located rurally. Although only $23.8 \%$ of the first cohort of CS professionals were placed rurally ${ }^{9}$, more recent studies have reported $55 \%$ of doctors, dentists and dieticians being allocated to rural placements ${ }^{19,58}$. In South Africa, $43.6 \%$ of the population live rurally ${ }^{58}$. Rural populations are least likely to have access to quality services ${ }^{59}$, carry a high burden of disease, and are served by a minority of health professionals ${ }^{60}$. A substantial number of CS professionals should be placed in these areas. However, defining 'rural locations' is not easy ${ }^{61}$. In this study a formal definition for 'rural' was not provided in the questionnaire so the percentage represented participants' perceptions of their allocation, rather than being based on objective criteria, such as receiving a rural allowance. Unfortunately, the overall urban/rural spread of the $2013 \mathrm{CS}$ occupational therapist population could not be ascertained from National Department of Health records.

Furthermore, close to half the participants (45.6\%) provided services at secondary and tertiary levels of care with more than a third (35\%) working solely within facility-based care. While it is not clear what level of service was provided at these facilities, and many may have provided outreach services to lower level facilities or communities, at least $73 \%$ of CS occupational therapists in 2013 were allocated to hospitals. This percentage is suggestive of a persistent hospital-centric trend within the public health system ${ }^{62}$. Lack of infrastructure at lower levels of care could have contributed to this trend.

Common reasons for referral reported by participants were largely related to physical health problems. It is possible that the nature of the questionnaire may have skewed responses towards capturing only some areas of the participants' practice, but it could also reflect the nature of daily practice. While it cannot be assumed that these referrals are reflective of overall community needs, they may, in part, represent the commonly understood role of the occupational therapist within the multidisciplinary team (MDT) as well as the community. They may also reflect the under-servicing of mental health needs in South Africa ${ }^{63}$, the practice preferences and experience areas of individual participants, or the continued dominance of the medical model orientation of the health system ${ }^{42,60}$. Referrals had a curative and rehabilitative focus and appeared to be largely focused on individual clients. Although CS has substantially increased access to OT within the public sector', it is clear that primary level services to rural populations still require prioritisation. A shift to a populationorientation $^{60}$, that includes promotive and preventative services and takes due cognisance of social determinants of health into account, are necessary for CS occupational therapy practice to align with the primary health care re-engineering policy ${ }^{64}$. Core principles of this policy also need to guide occupational therapy service development toward key health priorities and the burden of disease ${ }^{65}$.

Although it has been suggested that new graduates are not suited to rural practice ${ }^{43}$, in South Africa and abroad, having novice practitioners serving in rural areas is a reality ${ }^{49,66}$. CS has proven to be an effective recruitment strategy to increase health personnel in rural and under-served communities ${ }^{14}$. Although study participants were not asked whether they wished to continue in their post after CS, it is likely that they may not have wanted to do so given that CS is not an effective retention strategy ${ }^{14,67}$. Key findings of a Delphi study to identify South African rural health priorities ${ }^{59}$ echoed much of Reid's ${ }^{8}$ recommendations 10 years earlier and proposed interventions such as developing a national human resource plan that addresses the needs of rural contexts, appointing district and hospital managers with the appropriate experience and skills, equitable funding plans for hospitals, and the recruitment, retention and support of senior health professionals in rural hospitals ${ }^{59}$. With these strategies in place, it is likely that CS occupational therapists would be better situated, and thus better equipped for practice that is aligned with national, provincial and community guidelines and priorities. To effectively harness the CS occupational therapy workforce, the development of rural practitioners needs to receive greater attention. It has further been suggested that greater opportunities for rural practitioners to assume positions of leadership within the profession are required in order to contribute to a sound understanding of the skill set required for best practice in a rural setting ${ }^{68}$. If CS occupational therapists were supported and supervised by established rural practitioners, they would be better equipped to deliver services across the domains of occupational therapy practice.

As health care policy and decision makers need to work towards an effective human resource plan for health ${ }^{65}$, universities need to focus on preparing graduates appropriately. Burch and Reid $^{69}$ called for an explicit and pervasive orientation of university curricula towards rural practice with an emphasis on selecting students from rural and underserved areas. This appears to be the factor most strongly associated with rural practice ${ }^{70}$. Undergraduate clinical practice within a rural area (which is included in some undergraduate occupational therapy programmes in South Africa'") may prepare professionals for prolonged rural practice ${ }^{70}$ but it needs to occur early in the undergraduate programme and must include substantial clinical and community engagement with adequate supervision ${ }^{71}$. Acknowledging that 'assessment drives learning', the competencies for rural practice such as language and cultural competence, and resourcefulness, need to be examined.

The study results provide insight into the professional identity development of CS occupational therapists. Being able to appraise the contribution occupational therapy can bring to clients contributed a sense of pride in the profession that was related to a strong identity as an occupational therapist. The majority $(63.5 \%)$ felt that occupational therapy is poorly recognised largely due to a limited understanding of the role and value of occupational therapy which has been reported previously $y^{72-74}$. Identifying occupational therapists as physiotherapists has similarly been reported ${ }^{72}$. The perceptions of the MDT have been identified as important in the professional identity formation of novice therapists ${ }^{53}$. Another reason for the poor recognition of the profession is the lack of a title or descriptive term for the profession within some South African languages. The difficulty of communicating the nature and contribution of the profession within the English language has been reported as contributing to a lack of personal and professional identity in therapists ${ }^{75}$. If this applies to English language speakers, it is likely to be even more challenging for occupational therapists who speak a language in which occupational therapy terminology is non-existent. The role of appropriate supervision and the presence of occupational therapy colleagues appear to be crucial to early identity-formation in occupational therapists. The current study findings that novice therapists temporarily adopt the identity of colleague role-models until they develop an identity of their own, confirms previous studies ${ }^{72}$. In addition to the presence of supervision, CS occupational therapists and others ${ }^{72}$ have reported that various styles of supervision or supervision content are more helpful to identity formation than others.

This study revealed that witnessing what an occupation-centred approach contributes to the MDT and a growing focus on occupation-based practice appears to be critical to professional identity formation. It may also be this growing confidence in occupation that has a slow-but-sure ripple effect on the understanding of the profession within the team. Exploring the roles that occupational therapists assume in the MDT, Fortune ${ }^{46}$ queried whether new occupational therapists lacked examples of philosophically grounded practice, and feared that occupational therapists may only truly appreciate the essence of the profession over time or after postgraduate study.

To our knowledge this study was the first to document the general experience of CS occupational therapists II years after 
the implementation of CS for rehabilitation professionals. The questionnaire design which provided opportunity for commenting on responses to the close-ended questions enabled greater insights into participants' experiences. Although the names of all CS occupational therapists for 2013 were obtained, contact details were limited and their accuracy could not be verified; it is therefore not known whether all postal and text message invitations to participate reached the participants. It is also possible that many may have received the invitation but chose not to participate which may have introduced a non-response bias ${ }^{76}$. The response rate may also have been reduced by participants needing to provide their names on their responses. It is therefore unclear whether the study results may be generalised to the population of CS occupational therapists in 2013 , but they do provide valuable information about CS occupational therapists' experiences. Findings reflect the experiences of CS occupational therapists who completed their CS in 2013. Substantial changes to South African undergraduate occupational therapy curricula (including an increasing focus on rural practice) may have taken place since the graduation of this group of therapists. The relevance of findings may be limited by this.

\section{CONCLUSION}

Participants' experiences appeared to span the extremes of thriving and just surviving. Although many felt challenged and frustrated, a number reported satisfaction with their interaction with clients and were proud to be an occupational therapist. Results suggested that CS represents a crucial season in the professional identity formation of OTs and highlights the need for appropriate supervision and mentorship of CS occupational therapists. The study supports CS as a strategy that extends the reach of occupational therapy services within the public sector. However, the potency and potential of these novice professionals need to be nurtured and situated within the broader plans to increase access to occupational therapy services that are strategic, philosophically sound and aligned to government policy. Professional organisations and the National Department of Health need to develop strategies to retain experienced occupational therapists in underserved areas, and the public sector in general. Furthermore, while some mentorship structures for novice therapists exist within the Department of Health, these had not been documented at the time this study was conducted. This information should be shared to inform the development of a formalised supervision and mentorship system for this group as a matter of priority.

\section{ACKNOWLEDGEMENTS}

Gratitude is extended to the CS occupational therapists who willingly shared their experiences and the occupational therapists who assisted in refining the questionnaire.

The following funding sources are acknowledged for supporting the research project and publication:

* The KW Johnstone Award

$*$ Postgraduate Publication Incentive (PPI), University of Cape Town

\section{REFERENCES}

I. Harrison D. An overview of health and health care in South Africa 1994-20 10: Priorities, progress and prospects for new gains. Washington, DC: Henry J Kaiser Family Foundation, 2009 Dec.

2. Coovadia H, Jewkes R, Barron P, Sanders D and Mclntyre D. The health and health system of South Africa: historical roots of current public health challenges. Lancet, 2009; 374: 817-34.

3. Bloom G, Mclntyre $D$. Towards equity in health in an unequal society. Social Science \& Medicine, 1998; 30;47(10): 1529-38.

4. African National Congress. National Health Plan for South Africa. 1994. [cited 2014 Jan 15] Available from http://www.anc.org.za/ show.php?id $=257$.

5. Department of Health. White Paper for the Transformation of the Health System in South Africa. Government Gazette, 1997; 382(I7910).

6. Reid SJ. An overview of the first two years of community service. Health Systems Trust Update, 2000; 57: 6-7

7. Medical, Dental and Supplementary Health Service Professions Amendment Act 1997. Government Gazette, 1997; 390: I-56.

8. Reid SJ. Community service for health professionals. South African Health Review, 2002; 2002: 135-60.

9. Reid SJ. Compulsory community service for doctors in South Africa: an evaluation of the first year. South African Medical Journal, 200I; 9I(4): 329-36.

10. Holland KE, Middleton L, Uys L. Professional confidence: Conceptions held by novice occupational therapists in South Africa. Occupational Therapy International, 2013 Sep I; 20(3): I05-I3.

II. Maseko LJ, Erasmus A, Di Rago T, Hooper J, O'Reilly J. Factors that influence choice of placement for community service among occupational therapists in South Africa. South African Journal of Occupational Therapy, 2014 Jan; 44(I): 36-40.

12. Kolosa M. Community service in rural South Africa. South African Medical Journal, 2008 Jul 24; 93(8): 556.

13. Nemutandani MS, Maluleke FR, Rudolph MJ. Community service doctors in Limpopo province. South African Medical Journal, 2006 Mar I; 96(3): 180-2.

14. Ross A, Reid SJ. The retention of community service officers for an additional year at district hospitals in KwaZulu-Natal and the Eastern Cape and Limpopo provinces: original research. South African Family Practice, 2009; 5 I (3): 249 - 253.

15. Ramklass SS. Physiotherapists in under-resourced South African communities reflect on practice. Health \& Social Care in the Community, 2009 Sep I; I7(5): 522-9.

16. Thopola MK, Kgole JC, Mamogobo PM. Experiences of newly qualified nurses at University of Limpopo, Turfloop Campus executing community services in Limpopo Province, South Africa. African Journal for Physical, Health Education, Recreation and Dance, 2013 Mar I: 169-181.

17. Visser J, Marais M, Du Plessis J, Steenkamp I, Troskie I. Experiences and attitudes of dietitians during the first compulsory community service year (2003). South African Journal of Clinical Nutrition, 2006 Aug 29; 19(1): 10-7.

18. Paterson M, Green M, Maunder EM. Running before we walk: How can we maximise the benefits from community service dietitians in KwaZulu-Natal, South Africa?. Health policy, 2007 Aug 31;82(3):288301.

19. Parker WA, Steyn NP, Mchiza Z, Wentzel-Viljoen E, Dannhauser A, Mbhenyane X, Nthangeni G, Moeng L. Challenges for efficient health service delivery: experiences of dietitians completing their compulsory community service year in South Africa. Public Health Nutrition, 2012; 15(08): I4II-8.

20. Rohleder P, Miller M, Smith R. Doing time: Clinical psychologists' experience of community service in a prison placement. South African Journal of Psychology, 2006; 36(4): 795-8I 2.

21. Pillay AL, Harvey BM. The experiences of the first South African community service clinical psychologists. South African Journal of Psychology, 2006; 36(2): 259-80.

22. Swarts B. A community (dis) service: Reflections of a community service clinical psychologist. South African Journal of Psychology, 2013; 43(I): 105-15.

23. Flieringa $\mathrm{H}$. An exploration into the learning of occupational therapy students at a role-emerging service learning site in the Cape Metropole [unpublished masters minor dissertation]. Cape Town: University of Cape Town; 2006.

24. Beyers B. Experiences of community service practitioners who are deployed at a rural health facility in the Western Cape [unpublished minor dissertation]. Cape Town: University of the Western Cape; 2013.

25. Wranz ES. Compulsory Community Service for Speech-language and Hearing Therapy Professionals: Readiness, Reality and Readjustment [unpublished minor dissertation]. Cape Town: Stellenbosch University; 2011.

26. Gonlag J. City girl hits rural Mpumalanga. Focus, 2009: 9.

27. Millan F. Community Service Experience. Focus, 2012: 38.

28. Roane B. Reflections. Focus, 2010: 25.

29. Roux M. Community Service Experience. Focus, 20I2: 20. 
30. Stanton S, De Villiers C. What a year for Walmer girls. Focus, 20 I0: 12.

31. Sweidan L. What l've learnt. Focus, 2009: 8.

32. Tauby M. My Community Service Experience. Focus, 2009: 19.

33. Barnes K. Community Service. Focus, 2007: I5.

34. Barnard A. Community Service - a learning curve. Focus, 2007: 10.

35. Davies M. Community Service. Focus 2014: 30.

36. De Wit M. Community Service at Dr George Mukhari Hospital. Focus, 2012: 25.

37. Hackner N. Even a small difference can mean a lot. Focus, 2005: 2.

38. Joshi S. Community Service. Focus, 2008: 8.

39. Marshall S, Hawett C. Community Service Experience. Focus, 2008: 8-10.

40. Wright C. My Community Service. Focus, 2008: 8-9.

41. Bierman E, Burger H. Community Service in the town of the year - Sabie. Focus, 20I 3: 28

42. Hess-April L. Occupational Therapy graduates' conceptualizations of occupational justice in community service practice in South Africa: a UWC case study [unpublished dissertation]. Cape Town: University of the Western Cape; 2013.

43. Holland K, Middleton L, Uys L. Professional confidence: A concept analysis. Scandinavian Journal of Occupational Therapy, 2012; 19(2): 2I4-24.

44. Thomas R. Community Service News: A lifelong journey. Focus, 2009: 12 .

45. Nicolson T. Setting the stage - my community service year. Focus, 2009: 10 .

46. Fortune T, Ryan S, Adamson L. Transition to practice in supercomplex environments: Are occupational therapy graduates adequately prepared? Australian Occupational Therapy Journal, 2013; 60(3): 217-20.

47. Hodgetts S, Hollis V, Triska O, Dennis S, Madill H, Taylor E. Occupational therapy students' and graduates' satisfaction with professional education and preparedness for practice. Canadian Journal of Occupational Therapy, 2007; 74(3): 148-60.

48. Hummell J, Koelmeyer L. New graduates: perceptions of their first occupational therapy position. The British Journal of Occupational Therapy, 1999; 62(8): 35I-8.

49. Lee S, Mackenzie L. Starting out in rural New South Wales: the experiences of new graduate occupational therapists. Australian Journal of Rural Health, 2003; I I (I): 36-43.

50. Morley M. Moving from student to new practitioner: The transitional experience. The British Journal of Occupational Therapy, 2006; 69(5): 23I-3.

51. Morley M. Contextual factors that have an impact on the transitional experience of newly qualified occupational therapists. The British Journal of Occupational Therapy, 2009; 72(I I): 507-I4.

52. Robertson LJ, Griffiths S. Graduates' reflections on their preparation for practice. The British Journal of Occupational Therapy, 2009; 72(3): 125-32.

53. Toal-Sullivan D. New graduates' experiences of learning to practise occupational therapy. The British Journal of Occupational Therapy, 2006; 69(II): 513-24.

54. Wilding C, Curtin M, Whiteford G. Enhancing occupational therapists' confidence and professional development through a community of practice scholars. Australian Occupational Therapy Journal, 2012; 59(4): 312-8.

55. Fluidsurveys. Online and Mobile Surveys. [Cited 2014 Nov 19] Available from: www.fluidsurveys.com.

56. IBM. SPSS Statistics. [Cited 2016 Jun 6]. Available from: www.ibm. com/software/products/en/spss-statistics.

57. Szumilas M. Explaining Odds Ratios. Journal of the American Academy of Child and Adolescent Psychiatry, 2010; 19(3): 227-229.

58. National Department of Health Republic of South Africa. Human Resources for Health South Africa: HRH Strategy for the Health Sector: 2012/2013 to 2016/17. Pretoria; 20II.

59. Versteeg M, Du Toit L, Couper I. Building consensus on key priorities for rural health care in South Africa using the Delphi technique. Global Health Action, 2013; 6(19522): I 19-26.

60. Reid SJ. Rural health and transformation in South Africa. South African Medical Journal, 2006; 96(8): 676-7.

61. Humphreys JS. Delimiting 'rural': implications of an agreed 'rurality'index for healthcare planning and resource allocation.
Australian Journal of Rural Health, 1998; 6(4): 212-6.

62. Department of Health. National Health Insurance in South Africa.; 20I I:I-59. [cited 2016 Jun 6]. Available at: http://www.hst.org.za/ sites/default/files/2bcce6 I d2d I b8d972af4 I ab0e2c8a4ab.pdf.

63. Petersen I, Lund C. Mental health service delivery in South Africa from 2000 to 20 I0: one step forward, one step back. South African Medical Journal, 20I I; I0I(10): 75I-7.

64. Dookie S, Singh S. Primary health services at district level in South Africa: a critique of the primary health care approach. BMC Family Practice, 2012; 13(I): 67.

65. Naledi T, Barron P, Schneider H. Primary health care in SA since 1994 and implications of the new vision for $\mathrm{PHC}$ re-engineering. South African Health Review, 201 I: Dec 2.

66. Stagnitti K. Occupational therapy practice in rural and remote South Australia. Australian Journal of Rural Health, 2008; 16(5): 253-4.

67. Wilson NW, Couper ID, De Vries E, Reid SJ, Fish T, Marais BJ. A critical review of interventions to redress the inequitable distribution of healthcare professionals to rural and remote areas. Rural Remote Health, 2009; 9(2): 1060.

68. Lannin N, Longland S. Critical shortage of occupational therapists in rural Australia: Changing our long-held beliefs provides a solution. Australian Occupational Therapy Journal, 2003; 50(3): 184-7.

69. Burch V, Reid SJ. Fit for purpose? The appropriate education of health professionals in South Africa. South African Medical Journal, 20II; 10I(I): 25-6.

70. Grobler L, Marais BJ, Mabunda SA, Marindi PN, Reuter H, Volmink $J$. Interventions for increasing the proportion of health professionals practising in rural and other underserved areas. Cochrane Database, 2009; I (I).

7I. Reid SJ, Cakwe M. The contribution of South African curricula to prepare health professionals for working in rural or under-served areas in South Africa: A peer review evaluation. South African Medical Journal, 20II; I0I(I): 34-8.

72. Davis J. The importance of the community of practice in identity development. Internet Journal of Allied Health Sciences and Practice, 2006; 4(3): 5.

73. Tryssenaar J. The lived experience of becoming an occupational therapist. The British Journal of Occupational Therapy, 1999; 62(3): 107-12.

74. Hasselkus BR, Dickie VA. Doing occupational therapy: Dimensions of satisfaction and dissatisfaction. American Journal of Occupational Therapy, 1994; 48(2): 145-54.

75. Wilding C, Whiteford G. Language, identity and representation: Occupation and occupational therapy in acute settings. Australian Occupational Therapy Journal, 2008; 55(3): 180-7.

76. Berg N. MPRA. Munich Personal RePEc Archive: Non-response bias. 2010; (26373): I-34. [cited 2016 Jun6]. Available at: http:// mpra.ub.uni-muenchen.de/26373/I/MPRA_paper_26373.pdf.

Corresponding Author

Kirsty van Stormbroek

kirsty.vanstormbroek@wits.ac.za 